\title{
THE USE OF ULTRASONIC DENSITOMETRY IN ASSESSING BONE MINERAL DENSITY AND DETERMINING THE 10-YEAR RISK OF OSTEOPOROTIC FRACTURES IN OLDER WOMEN IN THE FAMILY DOCTOR PRACTICE
}

\section{Yevheniia Lukianets}

Osteoporosis is the fourth most common disease after cardiovascular, cancer and endocrine diseases. With an increase in life expectancy, it becomes one of the main causes of deterioration in health and an increase in mortality.

The aim of the study. To identify women with low bone density using ultrasound densitometry and assess the risk of osteoporotic fractures.

Materials and methods. The study was based on a survey of 31 women in the Odessa region, the average age of the subjects was $57 \pm 9.1$ years, the average body weight was $75.74 \pm 12.5 \mathrm{~kg}$, height $162.8 \pm 0.1 \mathrm{~cm}$, the average BMI was 28.57 \pm 4.5 . All women were divided into groups by age with a ten-year interval and by densitometry indices.

Results. Decrease in bone density was found in $51.6 \%$ of examined women. The lowest BMD was in the age group of 70-79 years, and the largest numbers of respondents with osteopenic changes were at the age of 50-59. A linear correlation was found between BMD and age at the level of significance $p=0.007$. The linear regression equation is: $t=-0.03968 *$ age $+1.268,(r=-0.473)$. In women with osteopenia, a significant increase in indicators was found for almost all algorithms for assessing the 10-year risk of fractures at $p<0.05$ (except for FRAX Hip without BMD $(p=0.087))$ and a significant decrease in ultrasound densitometry indicators compared with women with normal BMD. Women with fractures had significantly higher scores according to the FRAX Total algorithms without BMD ( $p=0.002)$, FRAX Hip without BMD ( $p=0.004)$ and Q-fracture Hip $(p=0.044)$.

Conclusions. Most women had osteopenic manifestations according to ultrasound densitometry. Age significantly correlates with BMD parameters. The numbers of women with changes in the structure of bone tissue increases with age, and, after 70 years, all women have osteopenic manifestations. The algorithms for assessing the 10-year risk of fractures FRAX and Q-Fracture reliably correlate with densitometry indicators. The combination of ultrasound densitometry with algorithms for assessing the risk of osteoporotic fractures significantly increases the diagnosis of osteoporosis Keywords: osteoporosis, osteopenia, ultrasonic densitometry, risk factors of osteoporosis, FRAX, Q-Fracture, family medicine

(C) The Author(s) 202

This is an open access article under the Creative Commons CC BY license hydrate

How to cite:

Lukianets, Y. (2021). The use of ultrasonic densitometry in assessing bone mineral density and determining the 10-year risk of osteoporotic fractures in older women in the family doctor practice. ScienceRise: Medical Science, 4 (43), 17-21. doi: http://doi.org/10.15587/2519-4798.2021.238027

\section{Introduction}

In developed countries, with increasing life expectancy, osteoporosis (OP) is becoming one of the leading causes of health loss and death, both among women and men [1]. In the structure of non-communicable diseases, OP occupies one of the key positions, ranking fourth in prevalence after cardiovascular, cancer and endocrine diseases [2]. OP is a major risk factor for allcause mortality in subjectively healthy older people (60 to 99 years), followed by type 2 diabetes mellitus (DM) and hypertension (HT), which requires more active diagnosis of OP in healthy individuals before they have OP-related incidents [3].

A survey of 17 primary care (PC) physicians in Stockholm, Sweden, found that most physicians considered OP to be a silent disease overshadowed by other conditions, emphasizing that they paid more attention to patients with diabetes, osteoarthritis, cardiovascular disease (CVD), and HT. That is, doctors perceive OP as a low-priority problem and emphasize the lack of aware- ness about this condition. There are differing opinions about who is responsible for managing patients with OP; doctors are not sure about the value of the fracture risk assessment tool (FRAX). They believe that financial incentives, education and expanded collaboration with other professionals and patients are needed to increase the priority of osteoporosis in PC [4].

Statistics show not only a tendency to increase the incidence of OP, but also a steady increase in the number of osteoporotic fractures (OPF), which is the main clinical outcome of the disease, significantly affecting morbidity, disability and mortality and economic costs of society $[5,6]$.

There are gender differences between fracture localization. For example, women are about 5 times more likely to have a forearm fracture, twice as likely to have a fracture of the spine or femur, which is partly due to the difference in BMD in adulthood, including postmenopausal bone tissue loss. In addition, women live longer, have a longer period of reduced BMD and other risk 
factors for OP, in particular, this is due to higher rates of comorbidities. Men have higher mortality rates from fractures [7]. The prevalence of OP in postmenopausal women is about $35-50 \%$, and mortality from hip fractures reaches $20 \%$ [8]. Increased risk of death persists for 10 years after fracture [9].

It is known that OPF increases the risk of subsequent fracture. A meta-analysis, 15,259 men and 44,902 women from 11 cohorts, showed that a previous history of fracture was associated with an $86 \%$ increase in the risk of fractures at any new site [10].

Clinical evaluation should consider all determinants of fracture risk, but bone mass assessment is the only aspect that can be easily measured in clinical practice used to diagnose, treat, predict risk, and monitor patients undergoing treatment. The diagnostic criterion for $\mathrm{OP}$ is based on the measurement of BMD - the amount of bone mass per unit volume (bulk density, $\left.\mathrm{g} / \mathrm{cm}^{3}\right)$ or per unit area $\left(\mathrm{g} / \mathrm{cm}^{2}\right)$. Both indicators can be measured in vivo using various densitometric methods [11]. Two-energy X-ray densitometry (DXA) is the reference standard for the diagnosis of OP, but this technique has significant shortcomings (inability to obtain three-dimensional images or information about bone microstructure), leading to insufficient diagnosis of the disease. In addition, total screening of BMD disorders is not appropriate, as it would exceed 2-10 times the cost of treatment of all potential OPFs [12].

To determine the OP in the absence of a fracture, T-score $\leq-2.5$ is taken; however, not all countries accept BMD as the sole criterion, as it has high specificity but low sensitivity (30-50 \%) - most OPF will occur in individuals with osteopenia or with BMD values above the osteoporosis threshold. Low sensitivity was the main reason not to recommend BMD testing for population screening $[13,14]$. Fracture risk assessment is improved by taking into account risk factors that act independently of BMD [15]. For example, age. The same T-score at any one site has different prognostic value at different ages, indicating that age contributes to risk regardless of BMD. Thus, taking into account age and BMD together increases the range of risks that can be identified [16].

However, there are additional factors that provide information about the risk of fractures regardless of age and BMD. 48 instruments are available to stratify patients at risk of fractures, but only some of them are validated. Among them are Osteoporosis Self-Assessment Tool; Osteoporosis Risk Assessment Instrument; Simple Calculated Osteoporosis Risk Estimation; Canadian Association of Radiologists and Osteoporosis Canada calculator; Fracture Risk Assessment Calculator (FRAX); Crow; and QFracture [6]. These tools assess clinical risk factors for OP to help determine if there is sufficient risk for further assessment with DXA [17].

The aim of the research. The aim of this study was to identify women with low bone density by ultrasound densitometry and to assess the risk of osteoporotic fractures.

\section{Materials and methods}

This study was conducted on the basis of the Department of "General Practice (Family Medicine)" of the National Medical University named after O. O. Bo- gomolets in 2019. The work was agreed at a meeting of the Commission on Bioethical Expertise and Ethics of Scientific Research at NMU named after O. O. Bogomolets No. 127 dated February 12, 2019. The study does not pose an increased risk to study subjects and is performed in accordance with existing bioethical norms and scientific standards in accordance with the requirements of good clinical practice (ICH GCP) and the Helsinki Declaration.

The study was based on a survey of 31 women in

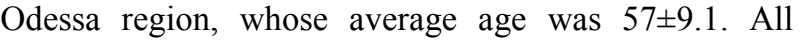
women were divided according to age into groups with a ten-year interval and by ultrasound densitometry.

The structural and functional condition of the bone tissue was assessed using a Hitachi Aloka AOS100E ultrasonic densitometer on the heel bone. Determined SOS (ultrasound rate, in $\mathrm{m} / \mathrm{s}$ ), TI (transmission index), OSI (bone ultrasound index), Z-score indices (comparison with the average rate in this age group) and T-score (comparison with the norm for middle-aged adult with "peak" bone mass). Changes in the structure of bone tissue were recorded in accordance with the criteria of the WHO (1994) on the T-score of bone mineral density (BMD), the subjects were divided into groups: T-score from +2.5 to -1 - normal; from -1.5 to -2.5 osteopenia; from -2.5 and below - osteoporosis [18].

The risk of fractures was calculated using online calculators FRAX and QFracture in women over 40 years $[19,20]$.

Anthropometric examination included determination of body weight and height. BMI was calculated according to the conventional formula.

Inclusion criteria: signed informed consent of the patient to participate in the study, female, age from 40 to 80 years.

Exclusion criteria: type 1 diabetes mellitus; exacerbation of chronic non-communicable diseases and diseases in the stage of decompensation; persons with oncological diseases; taking medications that may affect bone metabolism; pregnancy and lactation.

Statistical processing of the results was performed using statistical programs "Statistica 10.0" and "Microsoft Excel". The analysis for normality was performed by the Shapiro-Wilk method. Descriptive statistics are presented in the form of arithmetic mean and standard deviation, with minimum and maximum values. Qualitative characteristics are presented in the form of absolute values and percentages. Depending on the distribution of the characteristic, the comparison of parameters in the study groups was performed using the Student's test and the Mann-Whitney test. To study the nature and strength of the relationship between the studied indicators, we used the Pearson or Spearman correlation coefficient depending on the nature of the data distribution. Differences at $\mathrm{p}<0.05$ were considered statistically significant.

\section{Research results}

The study involved 31 women from Odessa region aged 40 to 79 years (mean age $57 \pm 9.1$ ), the main clinical indicators are presented in Table 1. Among women, 25 live in the city $(80.6 \%), 6(20.4 \%)$ - in rural areas. 
Table 1

The main clinical indicators of all patients included in the study

\begin{tabular}{|l|c|c|c|c|c|c|c|c|c|c|c|c|c|}
\hline $\begin{array}{l}\text { Age } \\
\text { (years) }\end{array}$ & $\begin{array}{l}\text { Number } \\
\text { of wo- } \\
\text { men (n) }\end{array}$ & \multicolumn{3}{|c|}{ Age, years } & \multicolumn{3}{c|}{ Weight, kg } & \multicolumn{3}{c|}{ Height, cm } & \multicolumn{3}{c|}{ BMI, kg/m ${ }^{2}$} \\
\hline $40-79$ & 31 & $57 \pm 9.1$ & 40 & 77 & $75.74 \pm 12.5$ & 54 & 101 & $162.8 \pm 0.1$ & 150 & 172 & $28.57 \pm 4.5$ & 21.3 & 36.7 \\
\hline
\end{tabular}

Note: data are presented as M SD, Min and Max - minimum and maximum values, BMI - body mass index

When studying the anamnesis of the subjects revealed diseases and comorbidities, which were classified on the basis of the International Classification of Diseases (ICD-10), the data are given in Tab. 2. In 16 women (45.7\%) 50 concomitant diseases were stated, i.e. on average 1.4 cases of concomitant pathology were accounted for each. It was found that the number and se- verity of comorbid diseases increased proportionally with age and was highest in older age groups.

The structure of concomitant pathology was dominated by diseases of the circulatory system (class IX 16 cases; $45.7 \%$ ) and digestive organs (class XI - 11; $31.4 \%$ ). (Table 2).

Table 2

The structure of concomitant pathology in women of Odessa region

\begin{tabular}{|c|c|c|c|}
\hline Disease class & Diagnosis & Quantity (n) & $\%$ \\
\hline \multirow{2}{*}{$\begin{array}{c}\text { Class IV. } \\
\begin{array}{c}\text { Diseases of the endocrine system, eating dis- } \\
\text { orders and metabolic disorders }\end{array}\end{array}$} & Diabetes mellitus & 1 & 2,8 \\
\hline & Diseases of the thyroid gland & 4 & 11.4 \\
\hline \multirow{3}{*}{$\begin{array}{c}\text { Class IX. } \\
\text { Diseases of the circulatory system }\end{array}$} & Hypertensive disease & 16 & 45.7 \\
\hline & Coronary heart disease & 3 & 8.6 \\
\hline & Vascular lesions of the brain & 2 & 5.7 \\
\hline \multirow{2}{*}{$\begin{array}{c}\text { Class X. } \\
\text { Respiratory diseases }\end{array}$} & COPD & 2 & 5.7 \\
\hline & Bronchial asthma & 5 & 14.3 \\
\hline \multirow{2}{*}{$\begin{array}{l}\text { Class XI. } \\
\text { Diseases of the digestive system }\end{array}$} & $\begin{array}{c}\text { Diseases of the gastrointestinal } \\
\text { tract }\end{array}$ & 5 & 14.3 \\
\hline & Liver disease & 6 & 17.1 \\
\hline $\begin{array}{c}\text { Class XIII. } \\
\text { Diseases of the musculoskeletal system and } \\
\text { connective tissue }\end{array}$ & Rheumatoid arthritis & 2 & 5.7 \\
\hline
\end{tabular}

At the time of the survey, all surveyed women denied alcohol abuse; smoking was confirmed by 3 women $(9.6 \%)$, and one smoked in the past $(3.2 \%)$. Five respondents $(16.1 \%)$ suffered bone fractures of different localization, and 12 subjects $(38.7 \%)$ reported femoral fractures or signs of osteoporosis in their parents; four women noted a decrease in growth after 40 years $(12.9 \%)$.

Gynecological anamnesis: pregnancy was in 29 women $(93.5 \%)$ - one child in $5(16.1 \%)$ women, two or more children in $24(77.4 \%)$ women; breastfeeding was present in $24(77.4 \%)$ women; periods of amenorrhea were diagnosed in 2 people $(6.5 \%)$; menopause before the age of 45 occurred in 4 respondents $(12.9 \%)$.
Insufficient consumption of dairy products was found in 16 women $(45.7 \%)$. Decreased physical activity was confirmed by 24 people $(68.6 \%)$. Three women have taken corticosteroids in the past $(9.6 \%), 4$ receive calcium supplements $(12.9 \%)$.

Osteopenic bone changes in women over 40 years of age were assessed by T-score, according to WHO recommendations. Decreased BMD was diagnosed in 16 women $(51.6 \%)$.

The lowest BMD was in the age group 70-79 years: $-1.96 \pm 0.5(p<0.01)$, and the largest number of respondents with osteopenic changes was found in the age group 50-59 years. The data are presented in Table 3.

Table 3

The ratio of BMD among age groups

\begin{tabular}{|c|c|c|c|c|c|c|}
\hline $\begin{array}{c}\text { Indicators / } \\
\text { Age groups, } \\
\text { years }\end{array}$ & $\begin{array}{c}\text { All women } \\
(\mathrm{n}=31)\end{array}$ & Quantity. \% & $\begin{array}{c}40-49 \\
(\mathrm{n}=5 ; 16.1 \%)\end{array}$ & $\begin{array}{c}50-59 \\
(\mathrm{n}=16 ; 51.6 \%)\end{array}$ & $\begin{array}{c}60-69 \\
(\mathrm{n}=6 ; 19.4 \%)\end{array}$ & $\begin{array}{c}70-79 \\
(\mathrm{n}=4 ; 12,9 \%)\end{array}$ \\
\hline BMD rate & $-0.35 \pm 0.4 \#$ & $15(48.4 \%)$ & $4(12.9 \%)$ & $7(22.6 \%)$ & $2(6.5 \%)$ & - \\
\hline Osteopenia & $-1.52 \pm 0.3 \#$ & $15(48.4 \%)$ & $1(3.2 \%)$ & $9(29 \%)$ & $4(12.9 \%)$ & $3(9,7 \%)$ \\
\hline Osteoporosis & -2.68 & $1(3.2 \%)$ & - & - & - & $1(3,2 \%)$ \\
\hline T-score & \multicolumn{2}{|c|}{$-0.99 \pm 0.7$} & $-0.69 \pm 0.7$ & $-0.77 \pm 0.6$ & $-1.17 \pm 0.6$ & $-1.96 \pm 0.5$ \\
\hline
\end{tabular}

Note: data are presented as $M \pm S D, T$-score - BMD; $*-p<0.01$ the difference is statistically significant between the age groups $70-$ 79 and 50-59 years; \# $-p<0.001$ the difference is statistically significant between normal values and osteopenia 
A linear correlation between BMD and age was found at a significance level of $p=0.007$. The linear regression equation has the form: $\mathrm{t}=-0.03968 *$ age +1.268 . The linear correlation coefficient $\mathrm{R}=-0.473$. With age, there is a decrease in the number of women with normal $\mathrm{BMD}$, and an increase in the number of women with osteopenic syndrome.
The 10-year risk of osteoporotic fractures was assessed with and without BMD using Q-fracture, FRAX algorithms. We found a statistically significant difference between normal and osteopenia in terms of BMD and algorithms, except for the FRAX Hir algorithm without BMD ( $\mathrm{p}=0.087)$. The obtained data are presented in Table 4.

Relationship between BMD and Q-fracture, FRAX algorithms with and without BMD

\begin{tabular}{|c|c|c|c|c|}
\hline Indicators of algorithms / Diseases & $\mathrm{P}$ & Norm $(48.4 \%)$ & Osteopenia (48.4 \%) & Osteoporosis (3.2 \%) \\
\hline Q-fracture Total, \% & 0.004 & $3.55 \pm 1.4 \#$ & $7.76 \pm 4.8 \#$ & 10.8 \\
\hline Q-fracture Hip, \% & 0.004 & $0.59 \pm 0.4 \#$ & $2.9 \pm 3.31 \#$ & 7.8 \\
\hline FRAX Total without BMD, \% & 0.026 & $6.8 \pm 5.9 \#$ & $7.92 \pm 5.3 \#$ & 9 \\
\hline FRAX Hip without BMD, \% & 0.087 & $1.16 \pm 1.8$ & $2.4 \pm 3.5$ & 2.7 \\
\hline FRAX Total, \% & 0.044 & $5.58 \pm 4.9 \#$ & $6.14 \pm 2.5 \#$ & 11 \\
\hline FRAX Hip, \% & 0.001 & $0.2 \pm 0.1 \#$ & $1.56 \pm 2.0 \#$ & 4.1 \\
\hline
\end{tabular}

Note: data are presented as $M \pm S D$, \#p - statistically significant difference between normal and osteopenia.

When evaluating the indicators in terms of age, it was determined that women aged 70-79 years had the highest 10-year risk of fractures by all algorithms: FRAX Total $-8.87 \pm 3.2$, FRAX Hip $-4.03 \pm 3.1$, Qfracture total $-12.87 \pm 1.5$, Qfracture Hip - 7.97 \pm 2.7 , FRAX Total without BMD - 11.9 \pm 5.5 , FRAX Hip without BMD - 6.3 \pm 4.8 . Significant differences were found according to the algorithm Q-fracture Total, Q-fracture Hir FRAX Hip, FRAX Hir without BMD p <0.01.

A significant correlation of the age of women with algorithms for calculating the 10-year risk of osteoporotic fractures FRAX Total without BMD ( $\mathrm{r}=-0.47$, $\mathrm{p}=0.007)$, FRAX Hip without BMD ( $\mathrm{r}=0.78, \mathrm{p}=0.006)$, Qfracture total ( $\mathrm{r}=0.86 \mathrm{p}=0.007)$, Qfracture Hip ( $\mathrm{r}=0.92$, $\mathrm{p}=0.008)$, FRAX Hip with BMD $(\mathrm{r}=0.55, \mathrm{p}=0.009)$. No statistically significant difference was found with FRAX Total and BMD ( $\mathrm{r}=0.21, \mathrm{p}=0.345)$.

Assessing BMD data and the 10-year risk of fractures in women without fractures and with fractures, we found that women with fractures significantly higher rates of FRAX Total without BMD ( $\mathrm{p}=0.002)$, FRAX Hir without BMD $(\mathrm{p}=0.004)$ and $\mathrm{Q}-$ fracture Hp $(\mathrm{p}=0.044)$.

\section{Discussion of research results}

All over the world much attention is paid to disease prevention. This important mission is mostly assigned to the doctor who first meets the patient - the family doctor. It so happened that in our country many doctors have little experience in the detection and prevention of osteoporosis and its complications. Some believe that this is the prerogative of narrow specialists.

Ultrasound densitometry is an effective method for screening for decreased bone mineral density. It can be used in both children and pregnant women. The devices are portable, high-speed and less expensive compared to dual-energy X-ray densitometry. At present, many studies have been conducted that confirm the high informativeness of this method, and when used with algorithms for assessing the risk of fractures increase the level of sensitivity and specificity of indicators to 90 and $100 \%$, respectively. Respondents with a history of osteoporotic fractures increase these rates to 95 and $60 \%$, and women without fractures to 87 and $92 \%$, respectively [21].

This study showed that the decrease in BMD progresses with age and the most vulnerable group are women over 70 years. And when comparing women with osteopenic manifestations and patients with normal bone density found a significant increase in all indicators: algorithms for predicting osteoporotic fractures and ultrasound densitometry in women with osteopenia.

Analyzing the performance of women with and without a history of fractures revealed that the algorithms, even without the use of BMD, are informative and can be used to assess the risk of osteoporotic fractures at the primary level of care.

The use of algorithms for assessing the 10-year risk of fractures helps the doctor to determine the need for the beginning of osteoporotic therapy, the appointment of DRA. The use of FRAX is more common, the advantage is the existence of the Ukrainian version and the possibility of using both with densitometry and without these indicators. The Qfracture algorithm uses English, but it is possible to assess the risk of fracture from one year and it contains an extended list of questions regarding the presence of concomitant pathology.

Questions about growth reduction after the age of 45 , the presence of fractures in the anamnesis of life and in parents, early menopause (up to 45 years), smoking, insufficient physical activity are highly informative and will help in the diagnosis of osteoporosis.

Study limitations. In the Odessa region, a survey was conducted on a small group of women. But they were able to quickly collect data in a relatively short period of time and clearly present how osteoporosis screening can be organized in the practice of a family doctor.

Prospects for further research. This issue needs more detailed study not only in relation to age, but also in relation to the region of the country and the conditions in which the respondents are. Ultrasound densitometry in combination with algorithms for assessing the risk of osteoporotic fractures can be used in epidemiological studies. 


\section{Conclusions}

According to ultrasound densitometry, most women had osteopenic manifestations. Age correlates significantly with BMD. That is, with age, the number of women with changes in bone structure increases. Moreover, after 70 years - all women had osteopenic manifestations.

Women with low BMD have significantly higher rates of 10-year fracture risk assessment algorithms (except FRAX Hir without BMD).

FRAX Total without BMD ( $\mathrm{p}=0.002)$, FRAX Hir without BMD $(p=0.004)$ and Q-fracture Hir $(p=0.044)$ were significantly higher in women with fractures.

The risk of FRAX and Q-fracture fractures is significantly correlated with densitometry. And questions about the reduction of growth after 45 years, the presence of fractures in the anamnesis of life and parents, early menopause (up to 45 years), smoking, insufficient physical activity are highly informative and significantly increase the risk of fractures in the subjects.

The combination of ultrasonic densitometry with algorithms for assessing the 10-year risk of osteoporotic fractures greatly increases the diagnosis of osteoporosis.

\section{Conflicts of interest}

The authors declare that they have no conflicts of interest.

Financing. The study was performed without financial support.

\section{References}

1. Svedbom, A., Hernlund, E., Ivergård, M., Compston, J., Cooper, C. et. al. (2013). Osteoporosis in the European Union: a compendium of country-specific reports. Archives of Osteoporosis, 8 (1-2). doi: http://doi.org/10.1007/s11657-013-0137-0

2. Smaliuh, O. Z. (2013). Osteoporosis: what should a practitioner know (a review of literature). Bukovinian Medical Herald, 17 (2), $168-171$.

3. Gutzwiller, J.-P., Richterich, J.-P., Stanga, Z., Nydegger, U. E., Risch, L., Risch, M. (2018). Osteoporosis, diabetes, and hypertension are major risk factors for mortality in older adults: an intermediate report on a prospective survey of 1467 communitydwelling elderly healthy pensioners in Switzerland. BMC Geriatrics, 18 (1). doi: http://doi.org/10.1186/s12877-018-0809-0

4. Salminen, H., Piispanen, P., Toth-Pal, E. (2019). Primary care physicians' views on osteoporosis management: a qualitative study. Archives of Osteoporosis, 14 (1). doi: http://doi.org/10.1007/s11657-019-0599-9

5. Curtis, E. M., Moon, R. J., Harvey, N. C., Cooper, C. (2017). The impact of fragility fracture and approaches to osteoporosis risk assessment worldwide. Bone, 104, 29-38. doi: http://doi.org/10.1016/j.bone.2017.01.024

6. El-Hajj Fuleihan, G., Chakhtoura, M., Cauley, J. A., Chamoun, N. (2017). Worldwide Fracture Prediction. Journal of Clinical Densitometry, 20 (3), 397-424. doi: http://doi.org/10.1016/j.jocd.2017.06.008

7. Cawthon, P. M. (2011). Gender Differences in Osteoporosis and Fractures. Clinical Orthopaedics Related Research, 469 (7), 1900-1905. doi: http://doi.org/10.1007/s11999-011-1780-7

8. Paul, T., Cherian, K., Kapoor, N. (2019). Utility of FRAX (fracture risk assessment tool) in primary care and family practice setting in India. Journal of Family Medicine and Primary Care, 8 (6), 1824-1827. doi: http://doi.org/10.4103/jfmpc.jfmpc_385_19

9. Bliuc, D., Nguyen, N. D., Milch, V. E., Nguyen, T. V., Eisman, J. A., Center, J. R. (2009). Mortality Risk Associated With Low-Trauma Osteoporotic Fracture and Subsequent Fracture in Men and Women. JAMA, 301 (5), 513-521. doi: http://doi.org/10.1001/jama.2009.50

10. Kanis, J. ., Johnell, O., De Laet, C., Johansson, H., Oden, A., Delmas, P. et. al. (2004). A meta-analysis of previous fracture and subsequent fracture risk. Bone, 35 (2), 375-382. doi: http://doi.org/10.1016/j.bone.2004.03.024

11. Blackie, R. (2020). Diagnosis, assessment and management of osteoporosis. Prescriber, 31 (1), 14-19. doi: http://doi.org/10.1002/psb.1815

12. Nayak, S., Edwards, D. L., Saleh, A. A., Greenspan, S. L. (2015). Systematic review and meta-analysis of the performance of clinical risk assessment instruments for screening for osteoporosis or low bone density. Osteoporosis International, 26 (5), 1543-1554. doi: http://doi.org/10.1007/s00198-015-3025-1

13. Leslie, W. D., Seeman, E., Morin, S. N., Lix, L. M., Majumdar, S. R. (2018). The diagnostic threshold for osteoporosis impedes fracture prevention in women at high risk for fracture: A registry-based cohort study. Bone, 114, 298-303. doi: http://doi.org/10.1016/j.bone.2018.07.004

14. Kanis, J. A., Johansson, H., Harvey, N. C., McCloskey, E. V. (2018). A brief history of FRAX. Archives of Osteoporosis, 13 (1). doi: http://doi.org/10.1007/s11657-018-0510-0

15. Burden, A. M., Tanaka, Y., Xu, L., Ha, Y.-C., McCloskey, E., Cummings, S. R., Glüer, C. C. (2020). Osteoporosis case ascertainment strategies in European and Asian countries: a comparative review. Osteoporosis International, 32 (5), 817-829. doi: http://doi.org/10.1007/s00198-020-05756-8

16. Medina-Gomez, C., Kemp, J. P., Trajanoska, K., Luan, J., Chesi, A., Ahluwalia, T. S. et. al. (2018). Life-Course Genome-wide Association Study Meta-analysis of Total Body BMD and Assessment of Age-Specific Effects. The American Journal of Human Genetics, 102 (1), 88-102. doi: http://doi.org/10.1016/j.ajhg.2017.12.005

17. Nayak, S., Edwards, D. L., Saleh, A. A., Greenspan, S. L. (2013). Performance of risk assessment instruments for predicting osteoporotic fracture risk: a systematic review. Osteoporosis International, 25 (1), 23-49. doi: http://doi.org/10.1007/s00198-013-2504-5

18. World Health Organization (1994). Assessment of fracture risk and its application to screening for postmenopausal osteoporosis. Technical Support Series. Geneva: WHO, 843.

19. Povorozniuk, V. V., Hryhorieva, N. V., Kanis, J. A., McCloskey, E. V., Johansson, H. (2016). Ukrainian FRAX version in the male osteoporosis management. News of Medicine and Pharmacy, 16 (596). Available at: http://www.mif-ua.com/archive/article/44043

20. Osteoporosis: assessing the risk of fragility fracture. NICE Clinical Guidelines, No. 146. London: National Institute for Health and Care Excellence. Available at: https://www.ncbi.nlm.nih.gov/books/NBK554920/

21. Povorozniuk, V. V., Hryhorieva, N. V., Povorozniuk, V. (2013). Ultrazvukova densytometriia v otsintsi strukturnofunktsionalnoho stanu kistkovoi tkanyny. Bol. Sustavi. Pozvonochnyk, 4 (12). Available at: http://www.mif-ua.com/archive/article/37833

Received date 18.05.2021

Accepted date 24.06.2021

Published date 30.07.2021

Yevheniia Lukianets, Postgraduate Student, Department of General Practice (Family Medicine), Bogomolets National Medical University, T. Shevchenko blvd., 13, Kyiv, Ukraine, 01601

E-mail: edyvnych@gmail.com 